\title{
Minimizing gear friction with water-containing gear fluids
}

\author{
Mustafa Yilmaz ${ }^{1}$ (D) $\cdot$ Thomas Lohner $^{1} \cdot$ Klaus Michaelis $^{1} \cdot$ Karsten Stahl $^{1}$
}

Received: 29 March 2019 / Accepted: 23 July 2019

(c) The Author(s) 2019

\begin{abstract}
Lubricants have a large influence on gear friction and therefore on gearbox losses and heat balance. Synthetic oils can exhibit significantly lower gear friction than mineral oils. Recent basic research on water-containing gear fluids has demonstrated superlubricity in highly-loaded elastohydrodynamically lubricated (EHL) contacts. Following up these results, the potential of water-containing gear fluids to improve the efficiency and heat balance of gearboxes was investigated. Experimental results from an efficiency gear test rig demonstrate significant lower load-dependent gear losses compared to mineral and polyalphaolefine oils. The mean coefficient of friction for a wide range of operating conditions is clearly smaller than 0.01 , which is referred to as superlubricity.
\end{abstract}

\section{Minimierung der Verzahnungsreibung mit wasserhaltigen Getriebefluiden}

\section{Zusammenfassung}

Schmierstoffe haben einen großen Einfluss auf die Reibung im Zahnkontakt und somit auf die Getriebeverluste und den Wärmehaushalt. Synthetische Schmierstoffe können im Vergleich zu Mineralölen eine deutlich niedrigere Verzahnungsreibung ermöglichen. Grundlagenuntersuchungen mit wasserhaltigen Getriebefluiden zeigen Supraschmierung im hochbelasteten elastohydrodynamischen (EHD) Kontakt. Auf Basis dieser Ergebnisse wurde das Potential wasserhaltiger Getriebefluide zur Verbesserung des Wirkungsgrades und Wärmehaushaltes von Getrieben untersucht. Experimentelle Untersuchungen am Zahnrad-Wirkungsgradprüfstand zeigen im Vergleich zu Mineralölen und Polyalphaolefinen deutlich niedrigere lastabhängige Verzahnungsverluste. Für einen Großteil der betrachteten Betriebsbedingungen sind die mittleren Verzahnungsreibungszahlen kleiner als 0,01, was den Bereich der Supraschmierung kennzeichnet.

\section{Abbreviations}

A Begin of contact [-]

b Face width $[\mathrm{Mm}]$

C Pitch point [-]

$\mathrm{C}_{\mathrm{a}} \quad$ Tip relief $[\mu \mathrm{m}]$

E End of contact [-]

$\mathrm{F}_{\mathrm{N}} \quad$ Normal tooth force $[\mathrm{N}]$

$\mathrm{H}_{\mathrm{VL}} \quad$ Local gear loss factor [-]

$\mathrm{M}_{\mathrm{n}} \quad$ Normal module [Mm]

$\mathrm{P}_{\mathrm{et}} \quad$ Transverse pitch $[\mathrm{Mm}]$

$\mathrm{p}_{C} \quad$ Hertzian pressure at the pitch point $[\mathrm{Pa}]$

P Power [W]

Mustafa Yilmaz

yilmaz@fzg.mw.tum.de

1 Gear Research Centre (FZG), Technical University of Munich (TUM), Boltzmannstraße 15, 85748 Garching near Munich, Germany

\begin{tabular}{ll}
$\mathrm{Ra}$ & Arithmetic mean roughness $[\mu \mathrm{m}]$ \\
$\mathrm{t}$ & Time [Min] \\
$\mathrm{T}$ & Torque $[\mathrm{Nm}]$ \\
$\mathrm{V}_{\mathrm{g}}$ & Sliding velocity $[\mathrm{m} / \mathrm{s}]$ \\
$\mathrm{V}_{\mathrm{t}}$ & Pitch line velocity $[\mathrm{m} / \mathrm{s}]$ \\
$\mathrm{z}$ & Number of teeth $[-]$ \\
\multicolumn{3}{c}{ Greek Symbols } \\
$\alpha_{\mathrm{n}}$ & Normal pressure angle $\left[{ }^{\circ}\right]$ \\
$\beta$ & Helix angle $\left[{ }^{\circ}\right]$ \\
$\varepsilon_{\alpha}$ & Transverse contact ratio $[-]$ \\
$\vartheta_{\mathrm{M}}$ & Gear tooth bulk temperature $\left[{ }^{\circ} \mathrm{C}\right]$ \\
$\vartheta_{\text {oil }}$ & Oil temperature $\left[{ }^{\circ} \mathrm{C}\right]$ \\
$\mu_{\mathrm{mz}}$ & Mean coefficient of friction $[-]$ \\
$v$ & Oil kinematic viscosity $\left[\mathrm{mm}^{2} / \mathrm{s}\right]$ \\
$\rho$ & Oil density $\left[\mathrm{Kg} / \mathrm{m}^{3}\right]$
\end{tabular}




$\begin{array}{ll}\text { Indices } & \\ 0 & \text { No-load } \\ 1 & \text { Pinion } \\ 2 & \text { Wheel } \\ \mathrm{B} & \text { Bearing } \\ \mathrm{G} & \text { Gear } \\ \mathrm{In} & \text { Input } \\ \mathrm{L} & \text { Loss } \\ \mathrm{P} & \text { Load-dependent } \\ \mathrm{S} & \text { Sealing }\end{array}$

\section{Introduction}

Due to the high importance of reducing energy consumption of drive units, a strong emphasis is put on the efficiency of gearboxes. The power loss of a gearbox includes power losses from gears, bearings, seals and auxiliaries. A differentiation is made between no-load and load-dependent losses. Lubricant viscosity and density strongly influence no-load losses such as churning, whereas lubricant base oils and additives strongly affect friction and therefore load-dependent losses. Power losses are directly related to gearbox heat balance.

Doleschel [1,2] and Michaelis et al.[3] developed a standard procedure for evaluating the gearbox losses and temperature behavior at the FZG gear efficiency test rig. Based on the test procedure, Hinterstoißer et al. [4, 5] performed a comprehensive study on various influence factors. They demonstrated an average reduction of gear friction by $36 \%$ for polyalphaolefine oil and $46 \%$ for polyether oil compared to mineral oil across all testing operating conditions. Ziegltrum et al. [6] verified the experimental results by thermal EHL simulations. Lohner et al. [7, 8] analyzed the influence of lubricant additives on gear friction at the FZG gear efficiency test rig and showed very low gear friction under boundary and mixed lubrication for plastic deformation (PD) additives. The mode of action of PD additives is referred to the in-situ decomposition of oil-soluble molybdenum dialkyldithiocarbamate (MoDTC) resulting in $\mathrm{MoS}_{2}$, which acts as a solid lubricant in asperity contacts.

Hinterstoißer et al. [4, 5] also investigated the influence of superfinished tooth flanks and demonstrated a reduction of gear friction by $20 \%$ compared to ground tooth flanks at low pitch line velocities. With an additional special run-in with low viscous oil, the reduction of gear friction was up to $35 \%$. Petry-Johnson et al. [9] showed similar results, which were explained by transient EHL simulations by $\mathrm{Li}$ et al. [10]. Lohner et al. [11] showed reduced gear friction with diamond-like carbon (DLC) coated tooth flanks under fluid film lubrication by up to $40 \%$ especially at high contact pressures and pitch line velocities. In this context, Ziegltrum et al. [12] conducted thermal EHL simulations explaining the reduction of friction by thermal insulation effects of DLC surfaces resulting in higher contact temperatures, lower effective viscosity and thus lower shear stress.

Hinterstoißer et al. [4, 5] and Moss et al. [13] investigated the influence of the oil level under dip lubrication and found lower gear friction for lower oil levels. Hence, additionally to the reduction of no-load losses, also gear friction was reduced due to higher gear bulk temperatures. Andersson et al. [14] showed a reduction of no-load losses for injection lubrication in comparison to dip lubrication especially at high velocities. Höhn et al. [15] confirmed these results and pointed out that injection lubrication with minimum quantities can result in low load carrying capacity due to thermal load limits.

Water-containing and water-based fluids have shown a large potential for achieving ultra-low friction with coefficients of friction smaller than 0.01 commonly referred to as superlubricity (Hirano et al. [16]). A water-based fluid can be referred to as liquid solution of water as base oil and additives (Sagraloff et al. [17]), whereas a water-containing fluid can be referred to a water-soluble base oil with significant water content. The origin of ultra-low friction for water-based fluids usually refers to the very low pressureviscosity coefficient resulting in low contact viscosity and shear stress (Martin et al. [18]). For pure water a pressureviscosity coefficient of $01 / \mathrm{GPa}$ is reported (Gohar [19]). In contrast, regarding water-containing fluids, an effective zone of a water shear layer formed in the lubricant film of the EHL contact is stated as the source of ultra-low friction (Li et al. [20], Li et al. [21], Wang et al. [22], Chen et al. [23]).

In a study preliminary to the present study, the authors investigated the film formation and frictional behavior of highly-loaded EHL contacts with water-containing gear fluids in fluid film lubrication regime (Yilmaz et al. [24]). Measurements at the optical EHL tribometer showed good lubricant film formation of the considered water-containing gear fluids due to their high pressure-viscosity coefficient and density. The pressure-viscosity coefficient was found to be in the order of $61 / \mathrm{GPa}$. Measurements at the twin-disk test rig showed ultra-low friction in superlubricity regime for all considered operating conditions.

The literature and the preliminary study by the authors indicate the large potential of water-containing fluids in significantly reducing gear friction and improving the efficiency and heat balance of gearboxes. Their potential is evaluated in this study by investigating the gearbox losses and temperature behavior with water-containing gear fluids at a gear efficiency test rig. 
Fig. 1 Mechanical layout of the FZG efficiency test rig according to Lohner [25]

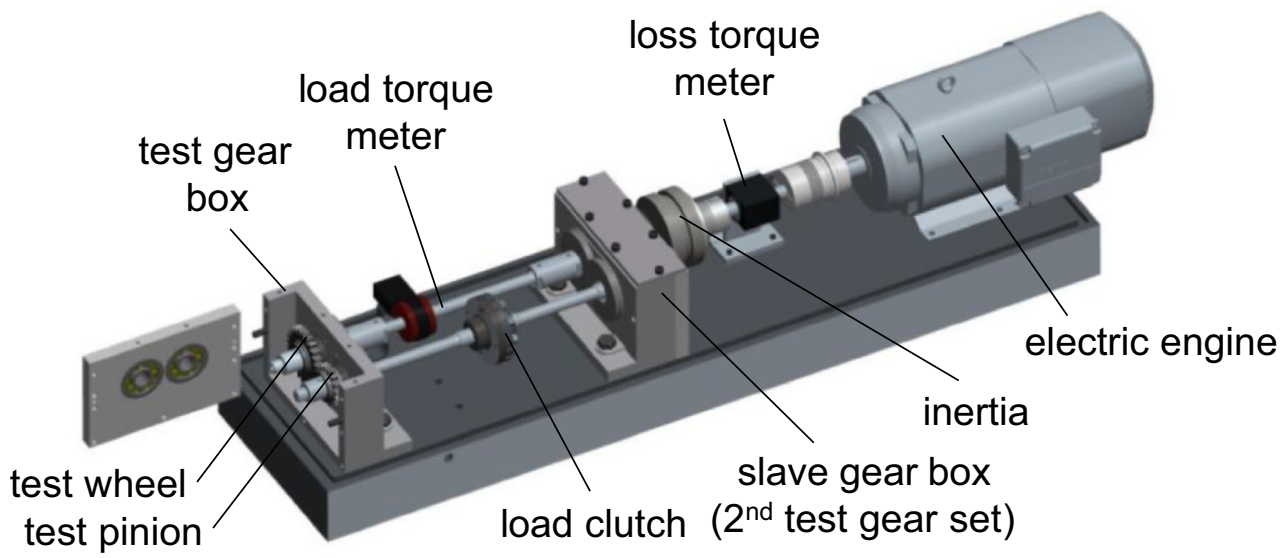

\section{Experimental setup}

This section describes the experimental setup of the considered gear efficiency test rig as well as the test gears, operating conditions and lubricants.

\subsection{Test rig}

Experiments at a FZG efficiency test rig are conducted to investigate the gearbox losses and temperature behavior with water-containing gear fluids. Fig. 1 shows the mechanical layout of the test rig in back-to-back configuration with a center distance of $91.5 \mathrm{~mm}$.

Only the main features of the test rig are described based on the description and wording of Lohner et al. [7]. For more details, the reader may refer to Hinterstoißer [5] and Lohner [25]. The FZG efficiency test rig is based on the principle of power circulation. The transmitted load torque is applied by a load clutch and measured by a load torque meter. The total loss torque is measured by a loss torque meter shaft mounted between the electric motor and the wheel shaft of the power circle. The load and loss torque are measured in addition to the shaft speeds, the oil sump temperature and the pinion bulk temperature. All pinion and gear shafts are supported by cylindrical roller bearings of type NU406 and NJ406 made of ceramic cylindrical rollers, cronidur@ races and a polyether ether ketone (PEEK) cage to avoid incompabilities with the water-containing lubricants. Radial shaft seals made of Viton are used. The vents of the test gearboxes are replaced by transparent pressure vessels in order to prevent evaporation of water and to monitor possible evaporation of water for operating conditions at high oil temperatures. Note that no obvious vaporization of water from the water-containing gear fluids was observed even for test runs at $\vartheta_{\text {Oil }}=90^{\circ} \mathrm{C}$.

The total loss $\mathrm{P}_{\mathrm{L}}$ of the power circle consists of the loaddependent gear loss $\mathrm{P}_{\mathrm{LGP}}$, the no-load gear loss $\mathrm{P}_{\mathrm{LG} 0}$, the load-dependent bearing loss $\mathrm{P}_{\mathrm{LBP}}$, the no-load bearing loss $\mathrm{P}_{\mathrm{LB} 0}$ and the sealing loss $\mathrm{P}_{\mathrm{LS}}$ :

$\mathrm{P}_{L}=\mathrm{P}_{\mathrm{LGP}}+\mathrm{P}_{\mathrm{LG} 0}+\mathrm{P}_{\mathrm{LBP}}+\mathrm{P}_{\mathrm{LB} 0}+\mathrm{P}_{\mathrm{LS}}$

When applying only a negligible load torque to the load clutch in the power circle, the measured total loss $\mathrm{P}_{\mathrm{L}}$ corresponds to the sum of the no-load losses. The load-dependent bearing loss $\mathrm{P}_{\mathrm{LBP}}$ can be either calculated or measured at a bearing test rig. In this study, the bearing losses are explicitly measured at the FZG bearing power loss test rig (Jurkschat et al. [26]) to improve measurement accuracy. Hence, the load-dependent gear loss $\mathrm{P}_{\mathrm{LGP}}$ can be determined by subtracting the sum of the no-load losses and the loaddependent bearing loss $\mathrm{P}_{\mathrm{LBP}}$ from the measured total loss $\mathrm{P}_{\mathrm{L}}$. Since the test gearboxes have the same gear pairs, the measured loss can be approximately halved in order to derive the load-dependent gear loss of one gearbox.

The load-dependent gear loss $\mathrm{P}_{\mathrm{LGP}}$ is the integral of the local distribution of the gear power loss along the path of contact. The influence of gear geometry is expressed by a numerically calculated local gear loss factor $\mathrm{H}_{\mathrm{VL}}$ (Wimmer [27]). Since the distribution of the coefficient of friction along the path of contact is unknown, a mean coefficient of

Table 1 Main gear parameters of FZG type $\mathrm{C}_{\text {mod }}$ gear

\begin{tabular}{|c|c|c|}
\hline & Pinion & Wheel \\
\hline Number of teeth $\mathrm{z}_{1}, \mathrm{z}_{2}$ & 16 & 24 \\
\hline Normal module $\mathrm{m}_{\mathrm{n}}$ in $\mathrm{mm}$ & 4.5 & \\
\hline Pressure angle $\alpha_{n}$ in ${ }^{\circ}$ & 20 & \\
\hline Helix angle $\beta$ in ${ }^{\circ}$ & 0 & \\
\hline Transverse contact ratio $\varepsilon_{\alpha}$ & 1.436 & \\
\hline Face width $\mathrm{b}$ in $\mathrm{mm}$ & 14 & \\
\hline Tip relief $C_{a}$ in $\mu \mathrm{m}$ & 35 & \\
\hline
\end{tabular}




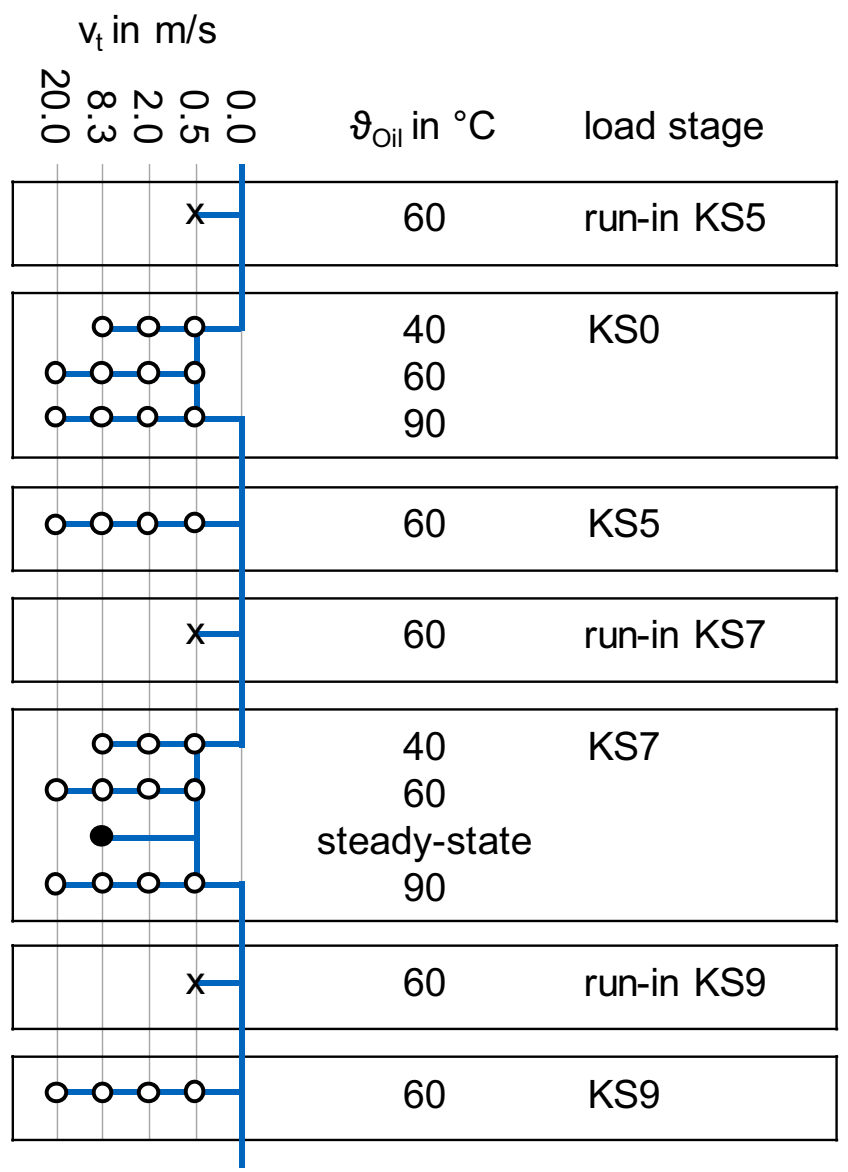

Fig. 2 Experimental approach at the FZG efficiency test rig (o: $\mathrm{t}=5 \mathrm{~min}, \mathrm{x}: \mathrm{t}=30 \mathrm{~min}, \boldsymbol{e}: \mathrm{t}=300 \mathrm{~min}$ )

friction $\mu_{\mathrm{mz}}$ is defined. Hence, the load-dependent gear loss $\mathrm{P}_{\mathrm{LGP}}$ can be written as

$\mathrm{P}_{\mathrm{LGP}}=\frac{1}{p_{\mathrm{et}}} \cdot \int_{\mathrm{A}}^{\mathrm{E}} \mathrm{F}_{\mathrm{N}}(\overline{\mathrm{y}}) \cdot \mu(\overline{\mathrm{y}}) \cdot v_{g}(\overline{\mathrm{y}}) \mathrm{d} \overline{\mathrm{y}}=\mu_{\mathrm{mz}} \cdot \mathrm{H}_{\mathrm{VL}} \cdot \mathrm{P}_{\mathrm{In}}$

where $\mathrm{P}_{\text {In }}$ is the transmitted power in the power circle.

\subsection{Test gears}

All experiments were conducted with FZG type $\mathrm{C}_{\text {mod }}$ gears with a tip relief of $C_{a}=35 \mu \mathrm{m}$ on pinion and wheel. The most important gear parameters are illustrated in Table 1.

The gears are made of case-carburized steel $16 \mathrm{MnCr} 5 \mathrm{E}$ (AISI 5115) with a surface hardness of $750 \mathrm{HV} 1$ and case-hardening depth of $\mathrm{CHD}_{550 \mathrm{HV} 1}=0.8-1.0 \mathrm{~mm}$. All gear flanks are ground and superfinished to an arithmetic mean roughness of $\mathrm{Ra}=0.14 \pm 0.03 \mu \mathrm{m}$. For surface roughness measurements, the profile method is used with a measurement length of $\mathrm{L}_{\mathrm{t}}=4 \mathrm{~mm}$ and a cut-off wavelength of $\lambda_{\mathrm{c}}=0.08 \mathrm{~mm}$. The roughness measurements are performed in involute direction perpendicular to the grinding direc-
Table 2 Load stages, torques and Hertzian pressures at the FZG efficiency test rig

\begin{tabular}{llll}
\hline $\begin{array}{l}\text { Load } \\
\text { stage } \\
\text { KS }\end{array}$ & $\begin{array}{l}\text { Pinion torque } \\
\mathrm{T}_{1} \text { in Nm }\end{array}$ & $\begin{array}{l}\text { Wheel torque } \\
\mathrm{T}_{2} \text { in Nm }\end{array}$ & $\begin{array}{l}\text { Hertzian pressure } \\
\text { pc in } \mathrm{N} / \mathrm{mm}^{2}\end{array}$ \\
\hline 0 & No-load & No-load & No-load \\
5 & 94.1 & 141.2 & 962.0 \\
7 & 183.4 & 275.1 & 1343.0 \\
9 & 302.0 & 453.0 & 1723.0 \\
\hline
\end{tabular}

tion. The local gear loss factors $\mathrm{H}_{\mathrm{VL}}$ in Eq. 2 are 0.165 for a pinion torque of $T_{1}=94.1 \mathrm{Nm}, 0.168$ for $T_{1}=183.4 \mathrm{Nm}$ and 0.174 for $\mathrm{T}_{1}=302.0 \mathrm{Nm}$.

\subsection{Operating conditions}

Fig. 2 shows the experimental approach at the FZG efficiency test rig, which is similar to the standard test by Doleschel [1,2]. In terms of the operating conditions, the only difference is in the oil temperature, which is varied between $\vartheta_{\text {oil }}=40$ and $90^{\circ} \mathrm{C}$ instead of 40 and $120^{\circ} \mathrm{C}$. Furthermore, the approach is rearranged from no-load to high load specified by the load stages KS0, KS5, KS7 and KS9. Table 2 relates the pinion torque $T_{1}$, wheel torque $T_{2}$ and Hertzian pressure at the pitch point $\mathrm{p}_{\mathrm{C}}$ to the load stages. A loadadjusted run-in at a low pitch line velocity of $\mathrm{v}_{\mathrm{t}}=0.5 \mathrm{~m} / \mathrm{s}$ and an oil temperature of $\vartheta_{\text {Oil }}=60^{\circ} \mathrm{C}$ was performed before each load stage for $30 \mathrm{~min}$.

All experiments were conducted under dip lubrication with an oil filling level of $76 \mathrm{~mm}(20 \mathrm{~mm}$ below the gear axes) at $40^{\circ} \mathrm{C}$. Hence, both pinion and wheel immerged with over full tooth height. The oil sump of the test gearboxes was cooled and heated in order to control the oil sump temperature $\vartheta_{\text {Oil }}$.

No-load (KS0) conditions were investigated for all considered oil temperatures of $\vartheta_{\text {Oil }}=\{40,60,90\}^{\circ} \mathrm{C}$ and pitch line velocities of $\mathrm{v}_{\mathrm{t}}=\{0.5,2.0,8.3,20.0\} \mathrm{m} / \mathrm{s}$. The influence of load (KS5, KS7, KS9) was investigated at $\vartheta_{\text {Oil }}=60^{\circ} \mathrm{C}$, the influence of oil temperature $\left(40^{\circ} \mathrm{C}, 60^{\circ} \mathrm{C}, 90^{\circ} \mathrm{C}\right)$ was investigated at KS7 for all pitch line velocities. The lubrication regimes extended from boundary to mixed and fluid film lubrication. Each operating condition was hold for $5 \mathrm{~min}$ to allow quasi-stationary conditions. Additionally, the steadystate temperature was evaluated for $300 \mathrm{~min}$ at KS7 and $\mathrm{v}_{\mathrm{t}}=8.3 \mathrm{~m} / \mathrm{s}$ without cooling or heating of the gearboxes.

For each lubricant, new gear pairs were used in order to avoid cross-influences of tribofilms. All experiments were repeated once. In Sect. 3, average values of the two test runs are shown. Error bars in bar charts indicate the result of test run one and two. 
Table 3 Properties of investigated lubricants

\begin{tabular}{lllllll}
\hline & \multicolumn{2}{l}{ Conventional gear oils } & \multicolumn{4}{c}{ Water-containing gear fluids } \\
& MIN-10 & PAO-09 & PAO-05 & PAGW-09 & PAGW-05A & PAGW-05B \\
\hline$v\left(40^{\circ} \mathrm{C}\right) \mathrm{in} \mathrm{mm}^{2} / \mathrm{s}$ & 94.1 & 50.2 & 20.4 & 45.7 & 23.6 & 22.9 \\
$v\left(100^{\circ} \mathrm{C}\right) \mathrm{in} \mathrm{mm}^{2} / \mathrm{s}$ & 10.6 & 9.0 & 5.0 & 9.2 & 5.3 & 4.8 \\
Viscosity index VI & 95 & 165 & 185 & 189 & 167 & 135 \\
$\rho\left(15^{\circ} \mathrm{C}\right)$ in $\mathrm{kg} / \mathrm{m}^{3}$ & 884.5 & 850.0 & 840.0 & 1115.0 & 1109.0 & 1097.0 \\
\hline
\end{tabular}

Fig. 3 Viscosity temperature behavior of the investigated lubricants according to DIN 51563

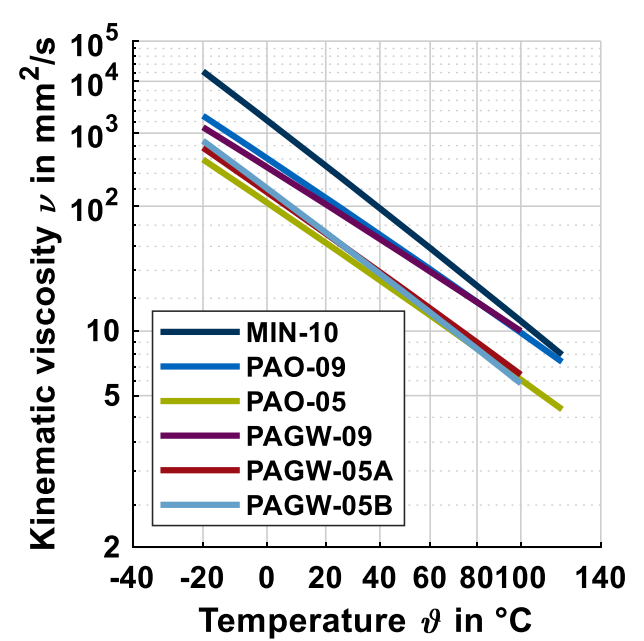

\subsection{Lubricants}

The considered lubricants were the same as used in preliminary basic study of the authors (Yilmaz et al. [24]). Three water-containing gear fluids were compared with conventional gear oils. Table 3 shows the corresponding kinematic viscosities and densities. The low viscosity levels of the considered lubricants mainly relates to applications in the automotive sector. The mineral oil MIN-10 is specified by Laukotka [28] and used as link to the results of Hinterstoißer [5]. The polyalphaolefine oils PAO-09 and PAO05 have the same base oil with typical gear oil additives incorporated. Its kinematic viscosity levels are specified at $100^{\circ} \mathrm{C}$ and differ strongly. The water-containing fluids PAGW-09, PAGW-05A and PAGW-05B are based on water-soluble polyalkylenglycols with water contents up to $70 \%$. Note that the given kinematic viscosities at $100^{\circ} \mathrm{C}$ are approximated. PAGW-09 and PAGW-05A have the same additives incorporated but have different kinematic viscosities, which are similar to PAO-09 and PAO-05. PAGW-05B has the same kinematic viscosity as PAGW-05A but different additives are incorporated. The densities of the watercontaining gear fluids are approximately $30 \%$ higher than those of conventional gear oils.

Fig. 3 illustrates the kinematic and dynamic viscosity over temperature according to DIN 51563 [29]. The various viscosity levels and indices are recognizable. Since the dynamic viscosity includes the influence of the lubricant density, the higher density of the water-containing gear fluids comes into effect.

\section{Results and discussion}

This section presents and discusses loss torques, mean coefficients of friction, steady-state excess temperatures, and tooth flank conditions.

\subsection{Loss torques}

Fig. 4 shows for all considered lubricants exemplarily the measured no-load losses $\mathrm{T}_{\mathrm{L} 0}$ and total losses $\mathrm{T}_{\mathrm{L}}$ at KS7 as well as derived load-dependent losses $\mathrm{T}_{\mathrm{LP}}$ at KS7 over the pitch line velocity $\mathrm{v}_{\mathrm{t}}$ for $\vartheta_{\text {oil }}=60^{\circ} \mathrm{C}$. Additionally, the measured pinion bulk temperature $\vartheta_{\mathrm{M} 1}$ is shown for KS7.

\subsubsection{No-load losses $T_{L 0}$}

The no-load loss curves in Fig. 4 show a steadily increasing trend for all lubricants. This is mainly due to increasing churning losses in the dip-lubricated test gearboxes. The influence of the lubricant on the no-load losses is primarily reflected by its kinematic viscosity and density. The dynamic viscosity as ratio of shear stress and shear rate may be a combined measure.

The differences between the conventional gear oils MIN10, PAO-09 and PAO-05 are small. In accordance with their 
Fig. 4 Measured no-load losses and total losses at KS7 as well as derived load-dependent losses and pinion tooth bulk temperatures over the pitch line velocity $\left(\vartheta_{\text {Oil }}=60^{\circ} \mathrm{C}\right)$
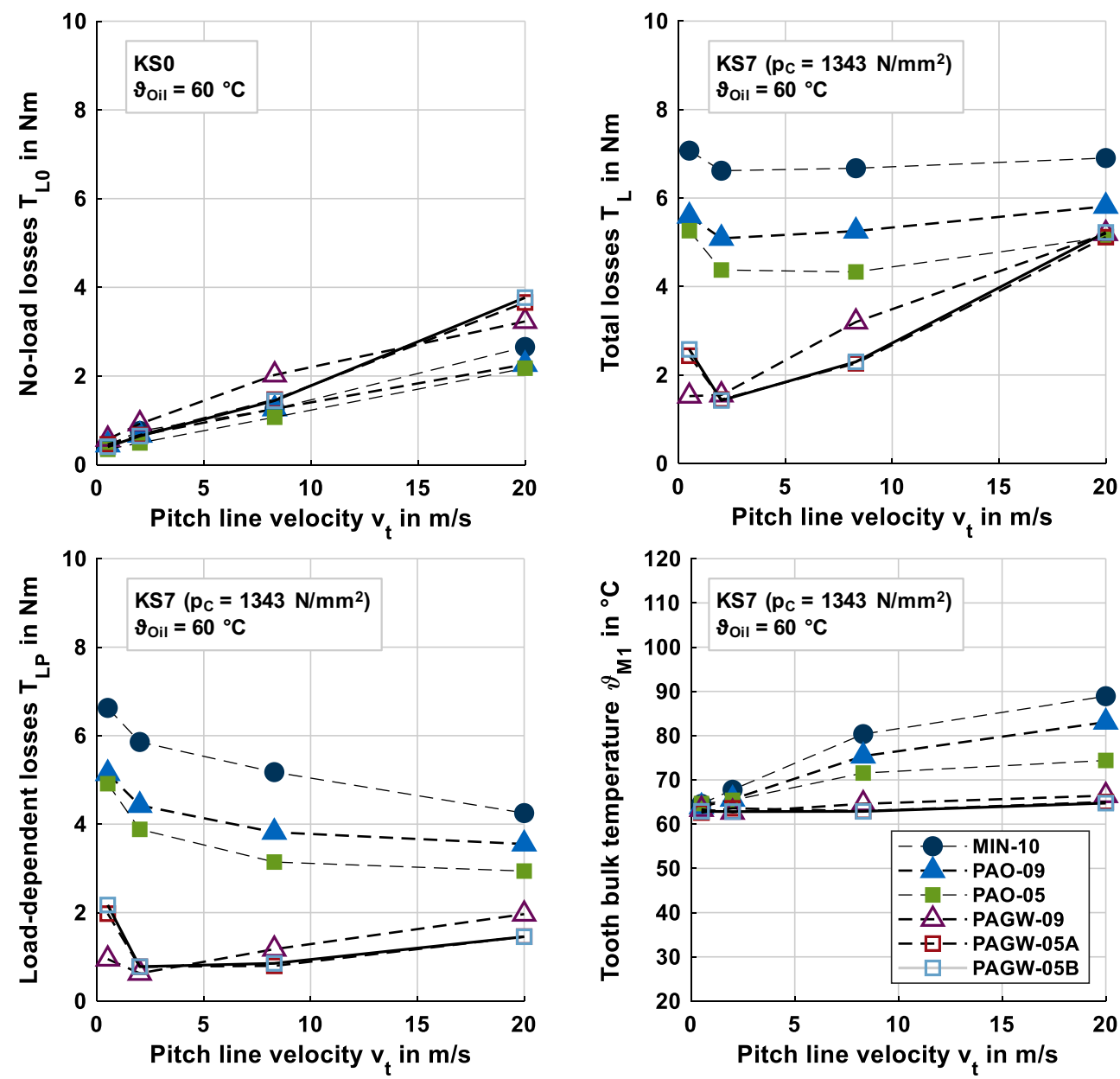

viscosities in Table 3, the highest no-load losses are measured with MIN-10 and the lowest with PAO-05. All of the water-containing gear fluids PAGW-09, PAGW-05A and PAGW-05B feature higher no-load losses than the conventional gear oils. This refers to the higher density of approximately $30 \%$. A classification according to the dynamic viscosities is not possible. PAGW-09, which has the highest viscosity of the water-containing gear fluids, has the highest no-load losses at low and medium pitch line velocities. The lower viscous water-containing gear fluids PAGW-05A and PAGW-05B show the same no-load losses, which are smaller than for PAGW-09 at low and medium pitch line velocities and higher at $\mathrm{v}_{\mathrm{t}}=20 \mathrm{~m} / \mathrm{s}$. The latter may be related to the formation of an empty air space around the gear in the oil sump, which is influenced by the pitch line velocity and lubricant.

\subsubsection{Total losses $T_{L}$}

The total loss curves in Fig. 4 consist of the no-load losses and the load-dependent losses. The general trends of the total loss curves are similar within the group of conven- tional gear oils (MIN-10, PAO-09, PAO-05) and within the group of water-containing gear fluids (PAGW-09, PAGW05A, PAGW-05B). The levels of total losses are remarkably different depending on the pitch line velocity $\mathrm{v}_{\mathrm{t}}$. At low values of $\mathrm{v}_{\mathrm{t}}$, the water-containing gear fluids show remarkably lower total losses than the conventional gear oils. With increasing values of $\mathrm{v}_{\mathrm{t}}$, the total losses of the water-containing gear fluids and the conventional gear oils approach and become almost equal at $\mathrm{v}_{\mathrm{t}}=20 \mathrm{~m} / \mathrm{s}$. This is influenced by the higher no-load losses of the water-containing gear fluids. To understand the behavior of the total loss curves, the loaddependent loss curves are discussed in the following.

\subsubsection{Load-dependent losses $T_{L P}$}

The load-dependent loss curves in Fig. 4 are obtained by subtracting the measured no-load losses from the measured total losses. The trend of the load-dependent loss curves is dominated by the lubrication regime, which gradually changes from boundary to mixed and fluid film lubrication with increasing pitch line velocity $\mathrm{v}_{\mathrm{t}}$. In boundary lubrication at low values of $v_{t}$, the influence of lubricant additives 
Fig. 5 Influence of pitch line velocity $\mathrm{v}_{\mathrm{t}}$ on the measured no-load and derived load-dependent losses at KS7 and $\vartheta_{\text {Oil }}=60^{\circ} \mathrm{C}$ for all investigated lubricants

Fig. 6 Influence of load stage on the measured no-load and $\mathrm{v}_{\mathrm{t}}=8.3 \mathrm{~m} / \mathrm{s}$ and $\vartheta_{\mathrm{Oil}}=60^{\circ} \mathrm{C}$ for all investigated lubricants derived load-dependent losses at
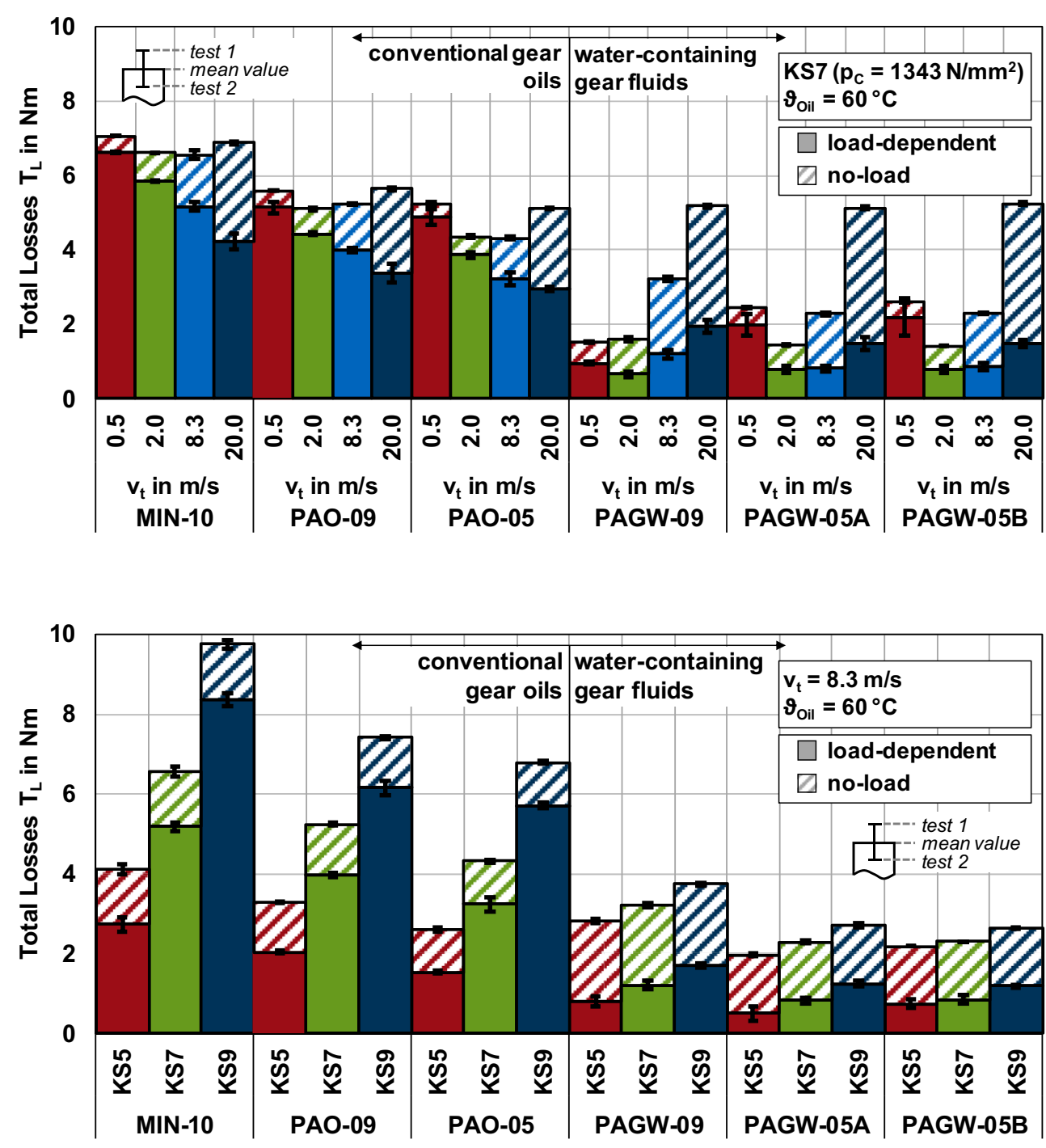

Fig. 7 Influence of oil temperature $\vartheta_{\text {Oil }}$ on the measured no-load and derived load-dependent losses at KS7 and $\mathrm{v}_{\mathrm{t}}=8.3 \mathrm{~m} / \mathrm{s}$ for all investigated lubricants

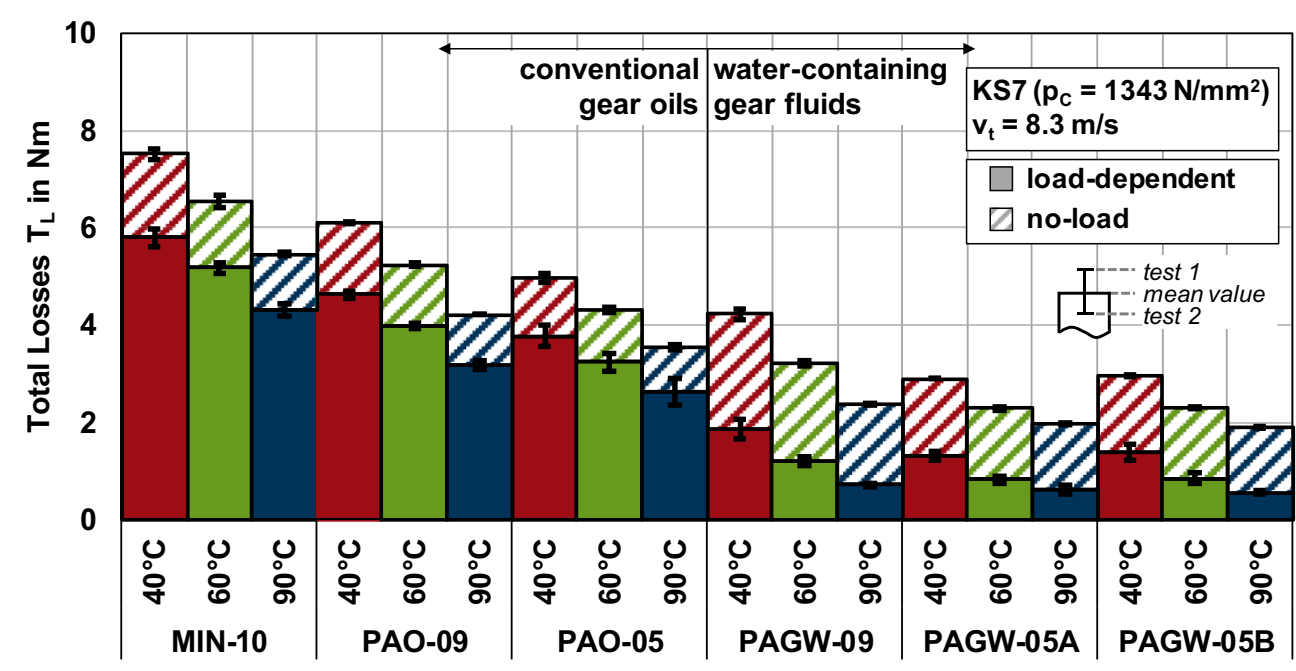


Fig. 8 Mean gear coefficients of friction $\mu_{\mathrm{mz}}$ over the pitch line velocity at $\vartheta_{\text {Oil }}=60^{\circ} \mathrm{C}$ for $\mathrm{KS} 7$ and KS9

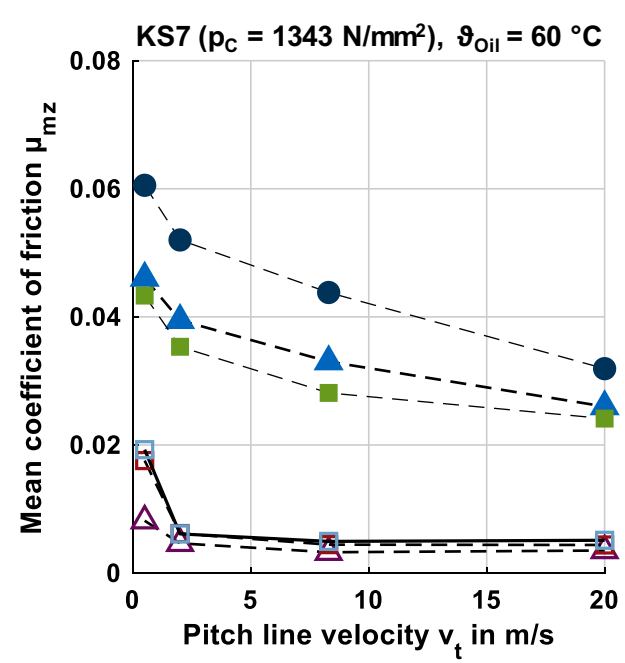

on load-dependent losses is high. In fluid film lubrication at high values of $v_{t}$, the influence of the base oil is high. Since the load-dependent losses still contain load-dependent gear and bearing losses, details on lubrication regimes and gear friction will be discussed in more detail by means of the mean coefficient of friction in Sect. 3.2.

Regarding the conventional gear oils MIN-10, PAO09 and PAO-05, the load-dependent loss curves decrease steadily with an increasing pitch line velocity $\mathrm{v}_{\mathrm{t}}$. The mineral oil MIN-10 exhibits higher load-dependent losses than the polyalphaolefine oils PAO-09 and PAO-05, whereas the lower viscous PAO-05 shows even lower losses than PAO-09. These findings correlate well with the general findings of Hinterstoißer [5]. At low values of $\mathrm{v}_{\mathrm{t}}$, the loaddependent losses decrease strongly with increasing $\mathrm{v}_{\mathrm{t}}$, because the lubrication regime transfers from boundary to mixed lubrication regime. At high values of $\mathrm{v}_{\mathrm{t}}$, the loaddependent losses decrease with increasing $\mathrm{v}_{\mathrm{t}}$ due to thermal effects (Hinterstoißer et al. [4]). The increase of the measured tooth bulk temperature $\vartheta_{\mathrm{M} 1}$ with pitch line velocity in Fig. 4 correlates with the load-dependent losses.

The water-containing gear fluids PAGW-09, PAGW-05A and PAGW-05B exhibit remarkably low load-dependent losses compared to the conventional gear oils. The loaddependent loss curves of the water-containing gear fluids decrease at low and increase at higher pitch line velocities $\mathrm{v}_{\mathrm{t}}$. PAGW-05A and PAGW-05B, which have a similar kinematic viscosity, shows almost the same load-dependent losses. Therefore, the different additives A and B are found to have no influence. PAGW-09 shows lower load-dependent losses at $\mathrm{v}_{\mathrm{t}}=0.5 \mathrm{~m} / \mathrm{s}$ and higher load-dependent losses at $\mathrm{v}_{\mathrm{t}}=\{8.3,20.0\} \mathrm{m} / \mathrm{s}$ than PAGW-05A and PAGW-05B, which refers to the higher viscosity of PAGW-09. Thermal effects have almost no influence on the load-dependent losses, since the increase of the tooth bulk temperature $\vartheta_{\mathrm{M} 1}$ with pitch line velocity is very small.
To provide a more complete overview on the influence of operating conditions and lubricants, Figs. 5, 6 and 7 summarize the no-load losses $\mathrm{T}_{\mathrm{L} 0}$ and the load-dependent losses $\mathrm{T}_{\mathrm{LP}}$ in bar charts.

Fig. 5 shows the measured no-load and derived loaddependent losses for pitch line velocities $\mathrm{v}_{\mathrm{t}}=\{0.5,2.0,8.3$, $20.0 \mathrm{~m} / \mathrm{s}$ at $\mathrm{KS} 7$ and $\vartheta_{\text {Oil }}=60^{\circ} \mathrm{C}$. It basically represents the results in Fig. 4 in bar chart form and clarifies that for conventional gear oils, the load-dependent losses are dominant for all pitch line velocities. In contrast, the loaddependent losses for water-containing gear fluids are very small, and the no-load losses become dominant for high pitch line velocities.

Fig. 6 shows the measured no-load and derived loaddependent losses for load stages KS5, KS7 and KS9 at $\mathrm{v}_{\mathrm{t}}=8.3 \mathrm{~m} / \mathrm{s}$ and $\vartheta_{\text {Oil }}=60^{\circ} \mathrm{C}$. For all lubricants, the load-dependent losses increase with load. For the conventional gear oils, the load-dependent losses are much higher and their relative increase with load is more pronounced than for the water-containing gear fluids. The no-load losses are independent of load and take for the conventional gear oils a much smaller share of the total losses than for the watercontaining gear fluids.

Fig. 7 shows the measured no-load and derived load-dependent losses for oil sump temperatures $\vartheta_{\text {oil }}=\{40,60,90\}^{\circ} \mathrm{C}$ at KS7 and $\mathrm{v}_{\mathrm{t}}=8.3 \mathrm{~m} / \mathrm{s}$. For all lubricants, the no-load and load-dependent losses decrease with increasing oil sump temperatures. Again, the load-dependent losses of the water-containing gear oils are very small, particularly for high oil sump temperatures. While the load-dependent losses are dominant for the conventional gear oils, the no-load losses are dominant for the water-containing gear fluids.

\subsection{Mean coefficient of friction}

Based on the measurement results, the mean coefficients of friction $\mu_{\mathrm{mz}}$ are derived according to Sect. 2.1. The measured 
bearing losses of all considered lubricants can be found in Yilmaz et al. [30]. Fig. 8 shows for all considered lubricants the derived mean coefficients of friction $\mu_{\mathrm{mz}}$ over the pitch line velocity $\mathrm{v}_{\mathrm{t}}$ for $\mathrm{KS} 7$ and $\mathrm{KS} 9$ and for $\vartheta_{\text {Oil }}=60^{\circ} \mathrm{C}$.

In general, the total gear friction in lubricated gear contacts is composed of fluid and solid friction. The individual shares depend on the lubrication regime and load sharing, i.e., how much of the total load is carried by asperity contacts and by the fluid due to hydrodynamics. The related solid friction in asperity contacts depends strongly on the lubricant additives, whereas the hydrodynamic fluid friction depends mainly on the lubricant base oil. For mineral oil with typical extreme pressure (EP) additive, the solid coefficient of friction is found to be higher than the fluid coefficient of friction (Lohner et al. [31]).

The portions of fluid and solid friction in Fig. 8 depend on the lubricant film thickness in the gear contact. The lubricant film thickness is small at low pitch line velocities $\mathrm{v}_{\mathrm{t}}$ and increases with increasing values of $\mathrm{v}_{\mathrm{t}}$. For the considered gear flank roughness, the lubrication regime changes gradually from boundary to mixed and fluid film lubrication. The influence of load on the lubricant film thickness is small (Mohrenstein-Ertel [32]).

In the study preliminary to the present study, experimental investigations at a twin-disk test rig were performed (Yilmaz et al. [24]). For fluid film lubrication with polished surfaces, the measured coefficient of friction was between $0.020 \leq \mu \leq 0.060$ for MIN-10, between $0.015 \leq \mu \leq 0.040$ for PAO-09 and PAO-05 and $\mu 0.008$ for the water-containing gear fluids PAGW-09, PAGW-05A and PAGW-05B. For all considered lubricants, a good lubricant film formation capability was found. At high pitch line velocities $\mathrm{v}_{\mathrm{t}}$, where the fluid friction is dominant, the mean coefficients of friction $\mu_{\mathrm{mz}}$ in Fig. 8 show relationships very similar to those observed at the twin-disk test rig (Yilmaz et al. [24]).

For the conventional gear oils MIN-10, PAO-09 and PAO-05, the mean coefficient of friction $\mu_{\mathrm{mz}}$ decreases steadily with increasing pitch line velocity $\mathrm{v}_{\mathrm{t}}$. Mainly due to its higher fluid friction, MIN-10 exhibits higher mean coefficients of friction than the polyalphaolefine oils PAO-09 and PAO-05. The influence of the lower viscosity of PAO05 compared to PAO-09 is small. These findings correlate well with general findings of Hinterstoißer [5]. At a low pitch line velocity of $\mathrm{v}_{\mathrm{t}}=0.5 \mathrm{~m} / \mathrm{s}$, the higher solid friction in asperity contacts determines the mean coefficient of friction. By increasing the pitch line velocity to $\mathrm{v}_{\mathrm{t}}=2.0 \mathrm{~m} / \mathrm{s}$, the lower hydrodynamic fluid friction gains influence and the mean coefficient of friction decreases. At higher pitch line velocities of $\mathrm{v}_{\mathrm{t}}=8.3 \mathrm{~m} / \mathrm{s}$ and $\mathrm{v}_{\mathrm{t}}=20.0 \mathrm{~m} / \mathrm{s}$, the mean coefficient of friction becomes dominated by fluid friction. Thermal effects due to increasing contact and tooth bulk temperatures (Fig. 4) result in a reduction of the effective contact viscosity, which further reduces fluid friction. The strongest thermal correction of the mean coefficient of friction is present for MIN-10.

Remarkably low mean coefficients of friction $\mu_{\mathrm{mz}}$ are found for the water-containing gear fluids PAGW-09, PAGW-05A and PAGW-05B. In fact, the derived mean coefficients of friction in a wide range of operating conditions are smaller than 0.01 , which is categorized as superlubricity. Its origin for the considered water-containing gear fluids may refer to an effective zone of a water shear layer formed in the lubricant films (Chen et al.[23]). Following an initial decrease at low pitch line velocities,
Fig. 9 Steady-state excess temperatures at $\mathrm{KS} 7$ and $\mathrm{v}_{\mathrm{t}}=8.3 \mathrm{~m} / \mathrm{s}$

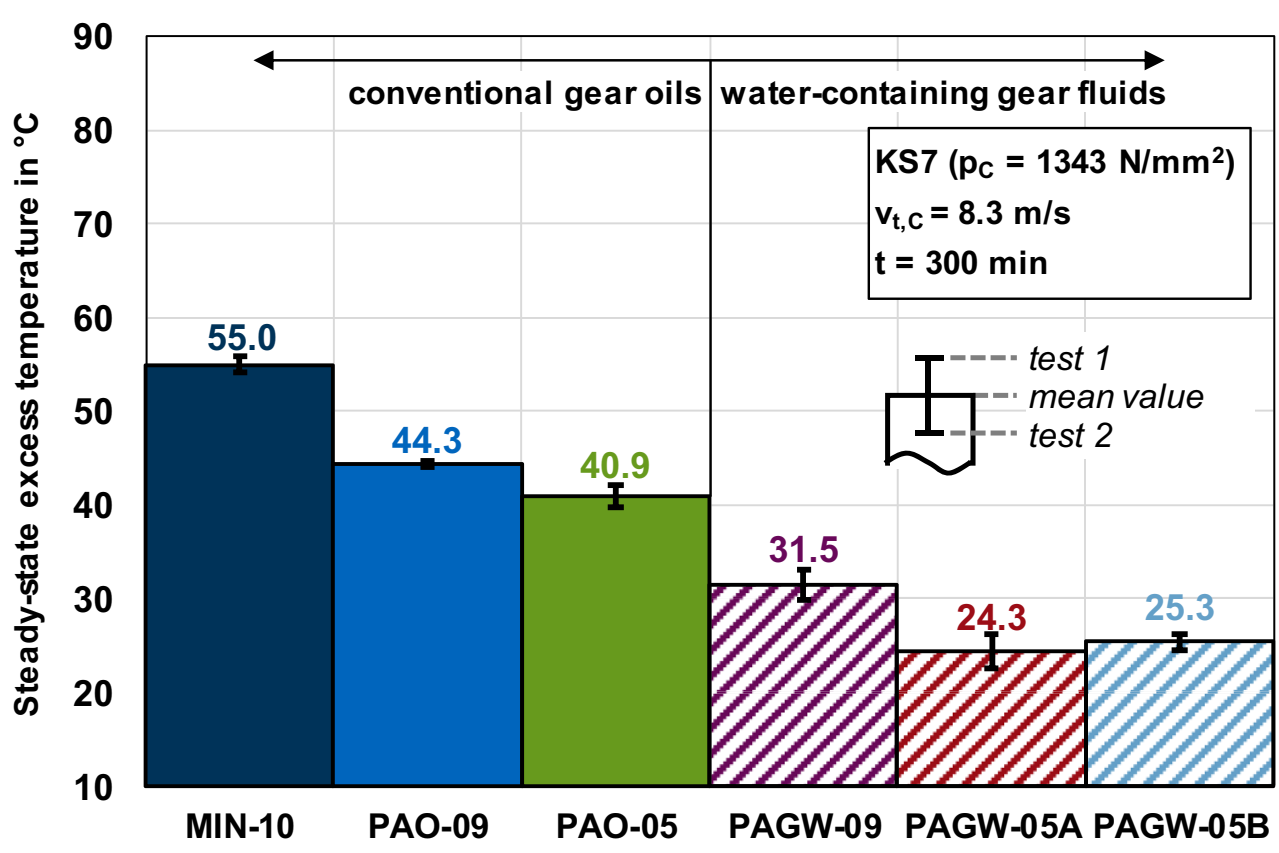


all friction curves exhibit a nearly constant mean coefficient of friction. As for the conventional gear oils, the higher solid friction in asperity contacts determines the mean coefficient of friction at the low pitch line velocity of $\mathrm{v}_{\mathrm{t}}=0.5 \mathrm{~m} / \mathrm{s}$. Due to the higher viscosity of PAGW-09, the lubricant film thickness is higher, hence the influence of low fluid friction on the mean coefficient of friction. The different additives in PAGW-05A and PAGW-05B show no significant influence. By increasing the pitch line velocity $\mathrm{v}_{\mathrm{t}}$, the ultra-low fluid friction of the water-containing gear fluids gains importance, and the mean coefficient of friction is kept at the level of superlubricity. Given that this results in low contact and tooth bulk temperatures (Fig. 4), thermal effects play almost no role for the water-containing gear oils.

Fig. 8 shows for the conventional gear oils higher mean coefficients of friction $\mu_{\mathrm{mz}}$ for load stage KS7 compared to load stage KS9. Almost no difference between load stage KS7 and KS9 is found for the water-containing gear fluids.

\subsection{Steady-state excess temperature}

The steady-state excess temperature is measured at KS7 and $\mathrm{v}_{\mathrm{t}}=8.3 \mathrm{~m} / \mathrm{s}$ without cooling or heating the gearboxes and relates to a stationary condition after a running time of $300 \mathrm{~min}$. It is calculated by the difference between the measured mean oil temperature of the two test gearboxes and the measured ambient temperature. Fig. 9 shows a comparison of the measured steady-state excess temperatures for all considered lubricants.

The measured steady-state excess temperatures correlate with the measured total losses shown in Fig. 4. The watercontaining gear fluids PAGW-09, PAGW-05A and PAGW05B exhibit significantly lower steady-state excess temperatures than the conventional gear oils MIN-10, PAO-09 and PAO-05. The lowest steady-state excess temperatures are measured with PAGW-05A and PAGW-05B. The results demonstrate the high level of potential for water-containing gear fluids in improving the heat balance of gearboxes.

\subsection{Tooth flank condition}

Surface roughness measurements, light microscope pictures and profile measurements were conducted before and after the efficiency test runs in order to analyze the tooth flank conditions. The surface roughness measurements of the superfinished gear flanks showed no significant changes when compared before and after efficiency testing. No significant smoothening or roughening of the tooth flanks was found. Light microscope pictures after efficiency testing showed only typical light markers and like the profile measurements no signs of wear.

\section{Conclusion}

This study investigated the gearbox losses and temperature behavior with water-containing gear fluids. Significantly reduced load-dependent losses were measured at the efficiency gear test rig in comparison to conventional gear oils. The derived mean coefficients of friction exhibited ultra-low friction with a reduction of up to $82 \%$. Over a wide range of operating conditions, the mean coefficients of friction are smaller than 0.01 , which is referred to as superlubricity. Almost no increase in gear tooth bulk temperature over pitch line velocity was found. In addition, the measurement of steady-state excess temperatures clarified the large potential for water-containing gear fluids in improving gearbox efficiency and heat balance.

Funding This publication uses results from a project that has been funded by the German Federal Ministry for Economic Affairs and Energy with funding reference $03 \mathrm{ET} 1286 \mathrm{H}$. The author is responsible for the content of this publication.

Open Access This article is distributed under the terms of the Creative Commons Attribution 4.0 International License (http:// creativecommons.org/licenses/by/4.0/), which permits unrestricted use, distribution, and reproduction in any medium, provided you give appropriate credit to the original author(s) and the source, provide a link to the Creative Commons license, and indicate if changes were made.

\section{References}

1. Doleschel A (2003) Wirkungsgradberechnung von Zahnradgetrieben in Abhängigkeit vom Schmierstoff [Efficiency calculation of gear drives depending on the lubricant. Dissertation, Technical University of Munich

2. Doleschel A, Michaelis K, Höhn B-R (2002) Method to Determine the Frictional Behaviour of Lubricants Using a FZG Gear Test Rig. Forschungsvereinigung Antriebstechnik e. V. issue, vol 345. FVA, Information Sheet

3. Michaelis K, Höhn B-R, Doleschel A (2009) Lubricant Influence on Gear Efficiency vol 6. ASME, pp 71-80. Proceedings of the ASME 2009 International Design Engineering Technical Conferences Computers and Information in Engineering Conference, IDETC/CIE 2009, August 30-September 2, 2009, San Diego, California, USA, DETC2009-86663

4. Hinterstoißer M, Sedlmair M, Lohner T, Stahl K (2019) Minimizing Load-Dependent Gear Losses. Tribologie und Schmierungstechnik, accepted

5. Hinterstoißer M (2014) Zur Optimierung des Wirkungsgrades von Stirnradgetrieben [On the optimization of the efficiency of spur gears. Dissertation, Technical University of Munich

6. Ziegltrum A, Lohner T, Stahl K (2017) TEHL simulation on the influence of lubricants on load-dependent gear losses. Tribol Int 113:252-261. https://doi.org/10.1016/j.triboint.2016.12.018

7. Lohner T, Stahl K (2017) Friction Reduction in Gearboxes by Plastic Deformation (PD) Additives. World Tribology Congress, Conference Proceedings

8. Lohner T, Merz R, Mayer J, Michaelis K, Kopnarski M, Stahl K (2015) On the Effect of Plastic Deformation (PD) Additives in. Lubr Tribol Schmierungstechnik vol 62(2):13-24 
9. Petry-Johnson TT, Kahraman A, Anderson NE, Chase DR (2008) An Experimental Investigation of Spur Gear Efficiency. J Mech Design 130:062601-1-062601-10. https://doi.org/10.1115/1.2898876

10. Li S, Kahraman A (2010) Prediction of Spur Gear Mechanical Power Losses Using a Transient Elastohydrodynamic Lubrication Model. Tribol Trans 53:554-563. https://doi.org/10.1080/ 10402000903502279

11. Lohner T, Ebner M, Ziegltrum A, Stahl K, Bobzin K, Brögelmann T (2018) Reduzierung der Flüssigkeitsreibungszahl durch DLC-Beschichtungen [Reduction of Fluid Coefficient of Friction with DLC Coatings]. Reibung in Antrieb und Fahrzeug 2018 - Bedeutung der Reibung im Wandel der Mobilität - 7. Atz-fachtagung Tribol Pp. https://doi.org/10.1007/978-3-658-25302-8_9

12. Ziegltrum A, Lohner T, Stahl K (2018) TEHL Simulation on the Influence of Lubricants on the Frictional Losses of DLC Coated Gears. Lubricants. https://doi.org/10.3390/lubricants6010017

13. Moss J, Kahraman A, Wink C (2018) An Experimental Study of Influence of Lubrication Methods on Efficiency and Contact Fatigue Life of Spur Gears. J Tribol 140:1-11. https://doi.org/10.1115/1. 4039929

14. Andersson M, Sosa M, Olofsson U (2017) Efficiency and Temperature of Spur Gears using Spray Lubrication compared to Dip. Lubr J Eng Tribol Vol 231:1390-1396. https://doi.org/10.1177/ 1350650117695709

15. Höhn B-R, Michaelis K, Otto H-P (2009) Minimised grear lubrication by a minimum oil/air flow rate. Wear 266:461-467. https://doi. org/10.1016/j.wear.2008.04.037

16. Hirano M, Shinjo K (1990) Atomistic locking and friction. Physical Review B, volume 41, number 17, pp. 11837-11851

17. Sagraloff N, Dobler A, Tobie T, Stahl K, Ostojewski J (2019) Development of an oil free water-based lubricant for gear apllications. Lubricants. https://doi.org/10.3390/lubricants7040033

18. Martin JM, De Barros-Bouchet MI (2014) Water-Like Lubrication of Hard Contacts by Polyhydric Alcohols. Aqueous Lubrication Natural and Biometric Approaches, pp 219-235

19. Gohar M (1988) Elastohydrodynamics. Imperial College. ISBN 085312-820-0, pp 20-24

20. Li J, Zhang C, Luo J (2013) Superlubricity Achieved with Mixtures of Polyhydroxy Alcohols and Acids. Langmuir 29:5239-5245. https://doi.org/10.1021/la400810c

21. Li J, Zhang C, Ma L, Liu Y, Luo J (2013) Superlubricity Achieved with Mixtures of Acids and Glycerol. Langmuir 29:271-275. https://doi.org/10.1021/la3046115
22. Wang H, Liu Y, Li J, Luo J (2016) Investigation of Superlubricity Achieved by Polyalkylene Glycol Aqueous Solutions. Adv Mater Interfaces 3:1600531. https://doi.org/10.1002/admi.201600531

23. Chen Z, Liu Y, Zhang S, Luo J (2013) Controllable Superlubricity of Glycerol Solution via Environment Humidity. Langmuir 38(29):11924-11930. https://doi.org/10.1021/la402422h

24. Yilmaz M, Mirza M, Lohner T, Stahl K (2019) Superlubricity in EHL Contacts with Water-Containing Gear Fluids. Lubricants. https://www.mdpi.com/2075-4442/7/5/46.. https://doi.org/ 10.3390/lubricants 7050046

25. Lohner T (2016) Berechnung von TEHD Kontakten und Einlaufverhalten von Verzahnungen [Calculation of TEHL contacts and running-in behaviour of gears. Dissertation, Technical University of Munich

26. Jurkschat T, Otto M, Stahl K (2015) Lebensdauer-IndustriegetriebeWälzlager [Lifetime. issue, vol 1145. Industrial, TransmissionsRoller Bearings]. Forschungsvereinigung Antriebstechnik e.V., FVA

27. Wimmer AJ (2006) Lastverluste von Stirnradverzahnungen - Konstruktive Einflüsse, Wirkungsgrad-maximierung, Tribologie [Load Losses of Spur Gears - Constructive Influences, Efficiency Maximization, Tribology. Dissertation, Technical University of Munich

28. Laukotka EM (2007) Referenzöle Datensammlung [Reference Lubricants Data Collection]. Forschungsvereinigung Antriebstechnik e. V. issue, vol 660. FVA. https://www.tib.eu/de/suchen/id/TIBKAT $\% 3$ A504191314/

29. DIN 51563 (1976) Prüfung von Mineralölen und verwandten Stoffen - Bestimmung des Viskosität-Temperatur-Verhaltens - Richtungskonstante [Testing of Mineral Oils and Related Materials Determination of Viscosity Temperature Relation].

30. Yilmaz M, Lohner T, Michaelis K, Stahl K (2019) Bearing Power Losses with Water-Containing Gear Fluids. Lubricants, submitted

31. Lohner T, Merz R, Mayer J, Michaelis K, Kopnarski M, Stahl K (2015) On the Effect of Plastic Deformation (PD) Additives in. Lubr Tribol Schmierungstechnik Vol 62(2):13-24

32. Mohrenstein-Ertel A (1984) Die Berechnung der hydrodynamischen Schmierung gekrümmter Oberflächen unter hoher Belastung und Relativbewegung [Calculation of hydrodynamic lubrication of curved surfaces under high load and relative velocity. VDI. https://www.tib.eu/de/suchen/id/TIBKAT\%3A025099132/ Die-Berechnung-der-hydrodynamischen-Schmierung/ 